\title{
Drought Tolerant Criterion of Wheat Genotypes Using Carbon Isotopes Discrimination Technique
}

\author{
Burhanuddin Rasyid ${ }^{1}$, Muhammad Ubaidullah Shirazi ${ }^{2}$, Joseph Adu Gyamfi ${ }^{3}$, T. Ram ${ }^{4}$ and Hamid Bachiri ${ }^{5}$ \\ 1. Dept. of Soil Science, Fac. of Agriculture, Hasanuddin University, Makassar 90245, Indonesia \\ 2. NIA (Nuclear Institute of Agriculture), Tando Jam 70060, Pakistan \\ 3. Joint FAO/IAEA Lab., Div. of Nuclear Techniques in Food and Agriculture, Seibersdorf A-2444, Austria \\ 4. Agricultural Research and Extension Unit, Quatre Bornes 80835, Mauritius \\ 5. INRAA (Institut National de Recherche Agronomique en, Algeria), Alger16200, Algeria
}

Received: March 10, 2015 / Accepted: March 25, 2015 / Published: April 25, 2015.

\begin{abstract}
Drought tolerant analysis using carbon isotopes discrimination could be useful tool to decide a genotype with high adaptation to drought. A pot culture experiment was conducted in glass house at the IAEA (International Atomic Energy Agency) laboratories, Seibersdorf, Austria to analyze drought tolerant of wheat genotype using carbon isotopes discrimination technique. Four wheat genotypes viz., LU-26s, Bhittai, Roshan, Taifu, were tested. There were two treatments: Control (normal irrigation) and Drought (@30\% field capacity of the control treatment). Drought treatment was imposed after two weeks of germination. The experiment was continued up to 10 weeks after germination and was terminated at flowering stage. The data were recorded in terms of plant height, number of tillers, shoot dry weight and carbon isotopic ratio $(\delta)$. Results showed that genotype LU-26s was found to have best performance under drought condition, with minimum decrease in the growth parameters i.e., plant height, number of tillers and shoot dry weight. High CID (carbon isotopes discrimination) values were also observed in genotype LU-26s, showing close positive correlation between SDW (shoot dry weight) and CID. It is therefore concluded that carbon isotopes discrimination can be an important criterion for the selection of wheat genotypes for drought prone areas.
\end{abstract}

Key words: Drought tolerant, carbon isotopes discrimination, wheat genotypes.

\section{Introduction}

Water could be limiting factor of plant growth. Drought during plant growth period will be reduced productivity. Wheat as an important cereal crop of the world is cultivated on the largest acreage in a wide range of climatic zones. The low rainfall and high temperatures are the serious threat to its low yield in arid and semi arid areas. In order to minimize the effects of drought and high temperatures, drought and heat tolerant varieties need to be evolved in addition to the judicious use of available irrigation water. Selection of suitable drought tolerant genotypes in the field is time consuming and difficult method for plant

Corresponding author: Burhanuddin Rasyid, Ph.D., research fields: soil, water and nutrient management. E-mail: burrasyid@unhas.ac.id. breeders. The use of carbon isotopes discrimination is an important nuclear technique to screen suitable genotypes for drought prone areas and is less time consuming. Plants discriminate between ${ }^{13} \mathrm{C}$ and ${ }^{12} \mathrm{C}$ during photosynthesis, they discriminate against ${ }^{13} \mathrm{C}$ during diffusion of $\mathrm{CO}_{2}$ through stomata and during the process of $\mathrm{CO}_{2}$ fixation by ribulose- 1.5 bisphosphate caroxylase (rubisco). The degree of discrimination against ${ }^{13} \mathrm{C}$ differs among species and varies with environments [1]. Carbon isotopes discrimination is a measure of the carbon isotopes composition in plant material relative to the value of the same ratio in the air on which plants feed. It can be expressed as:

$$
\Delta=(\delta \mathrm{a}-\delta \mathrm{p}) /(1+\delta \mathrm{p})
$$

where $\Delta$ represents carbon isotopes discrimination, $\delta \mathrm{a}$ represents $\mathrm{C}$ isotopes composition in air, and $\delta \mathrm{p}$ 
represents the $\mathrm{C}$ isotopes composition in plant tissue. It has been reported that there is a strong negative relationship between carbon isotopes discrimination $\Delta$ and water use efficiency of plants [2-5]. The present work was conducted to compare the response of some wheat genotypes to drought condition using carbon isotopes discrimination technique.

\section{Materials and Methods}

The studies were conducted in glass house at IAEA (International Atomic Energy Agency) laboratories, Seibersdorf, Austria. The day and night temperature was maintained between $20-25{ }^{\circ} \mathrm{C}( \pm 1)$. The experiment was arranged in a RCBD (randomized complete block design) with three replications. Four wheat genotypes viz., LU-26S, Bhittai, Roshan and Taifu, selected from different climatic zones, were tested in this study. The former two (LU-26S and Bhittai), were from Pakistan, one (Roshan), was from Iran and the later (Taifu) was from Germany. The study was conducted in pots containing 4 (four) $\mathrm{Kg}$ of Seibersdorf soil (soil type of Typic Eutrocrepts), plus sand mixed in 1:1 ratio. Six seeds were sown in each pot and three seedlings were maintained one week after germination till harvest. Each pot received a basal application of $20 \mathrm{~kg} \mathrm{~N}$ as ammonium sulphate (applied in 2 splits), $40 \mathrm{~kg} \mathrm{P}$ as super phosphate and $50 \mathrm{~kg} \mathrm{~K}$ as muriate of potash. The fertilizers were thoroughly mixed with soil using electric mixture. The drought treatment was imposed after two weeks of germination. The control plants were irrigated normally i.e., at field capacity whereas under drought treatment, water was applied at 30\% field capacity. The experiment was continued up to eighth week of germination and was terminated at physiological maturity i.e., at flowering stage. The growth observations (plant height, number of tillers) were recorded at the time of termination of experiment and dry eight was recorded after drying the samples in hot air oven after 72 hours. Carbon isotopes ratio $\left(C^{13} \&\right.$ $\mathrm{C}^{12}$ ) was determined by mass spectrometer (Isoprime,
UK) as described by Hubick et al. [6]. The data were subjected to analyze the differences of testing treatment using ANOVA (analysis of variance) and correlation analysis between treatments were determined by MStat-C computer package [7].

\section{Results}

\subsection{Growth Performance}

The results showed that there was a significant reduction in plant height, number of tillers and shoot dry weight of all the wheat genotypes due to drought treatment (Table 1).The data with respect to plant height showed a significant decrease due to drought treatment. However all the genotypes showed less than $50 \%$ reduction in plant height as compared to control treatment (i.e. normal irrigation). The genotype Roshan had the maximum plant height under control $(56.87 \mathrm{~cm})$ and minimum values for plant height were observed in LU-26s $(33.47 \mathrm{~cm})$. Whereas, under drought condition, the genotype Taifu had gained the maximum plant height $(34.0 \mathrm{~cm})$ and minimum plant height was recorded in Bhittai (25.57 $\mathrm{cm})$. It was also observed that although the genotype LU-26s had minimum plant height under drought condition but had maintained it successfully as it showed only $31 \%$ reduction under drought. On the other hand, the genotype Roshan showed the maximum reduction $(42.0 \%)$ under drought, indicating its sensitivity to drought.

The tillering capacity of the wheat genotypes was also reduced due to low soil moisture availability. Maximum number of tillers under both treatments (control \& drought) was observed in LU-26s (4.75 and 3.76 tillers/plant, respectively). The genotype LU-26s also had maintained the number of tillers quite successfully with minimum reduction i.e., only $21.0 \%$. On the other hand, while evaluating crop plants against the genotype Taifu showed maximum reduction (39.7\%). The SDW (shoot dry weight) is an important consideration of drought tolerant plant, as it reflects the amount of photosynthate produced during 
Table 1 Growth performance of some wheat genotypes under control and drought condition.

\begin{tabular}{|c|c|c|c|c|c|c|}
\hline \multirow{3}{*}{ Genotypes } & \multicolumn{2}{|c|}{ Plant height (cm) } & \multicolumn{2}{|c|}{ Numbers of tillers } & \multicolumn{2}{|c|}{ Shoot dry weight (g) } \\
\hline & \multicolumn{6}{|c|}{ Treatments } \\
\hline & Control & Drought & Control & Drought & Control & Drought \\
\hline Roshan & $56.87 \mathrm{a}$ & $\begin{array}{l}33.00 \mathrm{~b} \\
(41.97)\end{array}$ & $3.57 \mathrm{~b}$ & $\begin{array}{l}2.43 \mathrm{~b} \\
(31.93)\end{array}$ & $7.01 \mathrm{c}$ & $\begin{array}{l}3.57 \mathrm{~b} \\
(49.07)\end{array}$ \\
\hline Taifu & $51.47 \mathrm{~b}$ & $\begin{array}{l}34.00 \mathrm{ab} \\
(33.94)\end{array}$ & $3.70 \mathrm{~b}$ & $\begin{array}{l}2.23 \mathrm{bc} \\
(39.73)\end{array}$ & $8.44 \mathrm{a}$ & $\begin{array}{l}3.87 \mathrm{ab} \\
(54.15)\end{array}$ \\
\hline LU-26s & $33.47 \mathrm{~d}$ & $\begin{array}{l}23.00 \mathrm{c} \\
(31.28)\end{array}$ & $4.76 \mathrm{a}$ & $\begin{array}{l}3.76 \mathrm{a} \\
(21.01)\end{array}$ & $7.85 \mathrm{ab}$ & $\begin{array}{l}4.33 \mathrm{a} \\
(44.84)\end{array}$ \\
\hline Bhittai & $43.23 \mathrm{c}$ & $\begin{array}{l}25.57 \mathrm{c} \\
(40.85)\end{array}$ & $3.00 \mathrm{~b}$ & $\begin{array}{l}2.10 \mathrm{bc} \\
(30.00)\end{array}$ & $8.26 \mathrm{a}$ & $\begin{array}{l}3.99 \mathrm{ab} \\
(51.69)\end{array}$ \\
\hline LSD $(0.05 \%)$ & 6.744 & & 0.9771 & & 0.647 & \\
\hline LSD (0.05\%) & 6.744 & & 0.9771 & & 0.647 & \\
\hline
\end{tabular}

* Values in parenthesis are the $\%$ reduction over control;

** The values having the same letter in same column are statistically similar at $5 \%$ level.

the particular growth period of plant under stress condition. The shoot dry weight was also reduced significantly with the induction of drought treatment. The genotype LU-26s had maximum SDW values under drought treatment $(4.33 \mathrm{gm})$ indicating minimum reduction (i.e., 44\%) in SDW under drought as compared to other genotypes.

It was also observed that the two genotypes i.e., Taifu and Bhittai, which were showing maximum shoot dry weight under control treatment, could not maintain their SDW under drought, showing 52\% and $54 \%$ reduction, respectively. The differences within the genotypes were significant under both the treatments when compared statistically.

\subsection{Carbon Isotopes Discrimination (4)}

Shoot samples analysed for isotopic ratio of ${ }^{13} \mathrm{C}$ to ${ }^{12} \mathrm{C}$, showed that the wheat genotypes discriminate effectively between ${ }^{12} \mathrm{C} /{ }^{13} \mathrm{C}$ under both water regimes, however the $\triangle$ values decreased under drought compared to normal irrigation (Fig. 1).

The $\Delta$ values varied from $19.66 \%$ to $21.68 \%$ under normal irrigation and $18.31 \%$ to $20.36 \%$ under drought condition. The $\Delta$ values also varied among the genotypes under both water regimes. Under normal irrigation the genotype Taifu had the maximum $\Delta$ value $(20.81 \%)$ followed by Roshan $(20.63 \%)$. The
(CID) value was also observed maximum in Taifu under drought condition.

The relative decrease in $\Delta$ values showed that the genotype Roshan and Taifu had more reduction (i.e., $8.21 \%$ to $8.71 \%$ ) under drought condition (Fig. 2). On the other hand, it was observed that though the genotype LU-26s had less $\Delta$ values under control conditions but had maintained it quite satisfactorily under drought conditions, with only $6.28 \%$ reduction. The higher decrease in CID values in case of Taifu (8.71\%) and Roshan (8.21\%) indicated higher sensitivity to drought in these genotypes.

\section{Discussion}

The carbon isotopes discrimination can prove an important criterion for the selection of wheat genotypes for drought prone areas. In the present study, positively close relationship $(\mathrm{R} 2=0.7187)$ between SDW and CID $\triangle$ was observed (Fig. 3). The decrease in $\Delta$ values under drought stress showed a general trend of less discrimination under stress conditions compared to well watered conditions. According to Farquhar et al. [8], a shift in the carbon isotope discrimination of the leaf tissues due to stress gives an information about the plant succeeded in maintaining WUE (water use efficiency) and confirms the stress induced changes in the $\mathrm{Ci} / \mathrm{Ca}$ ratio. 


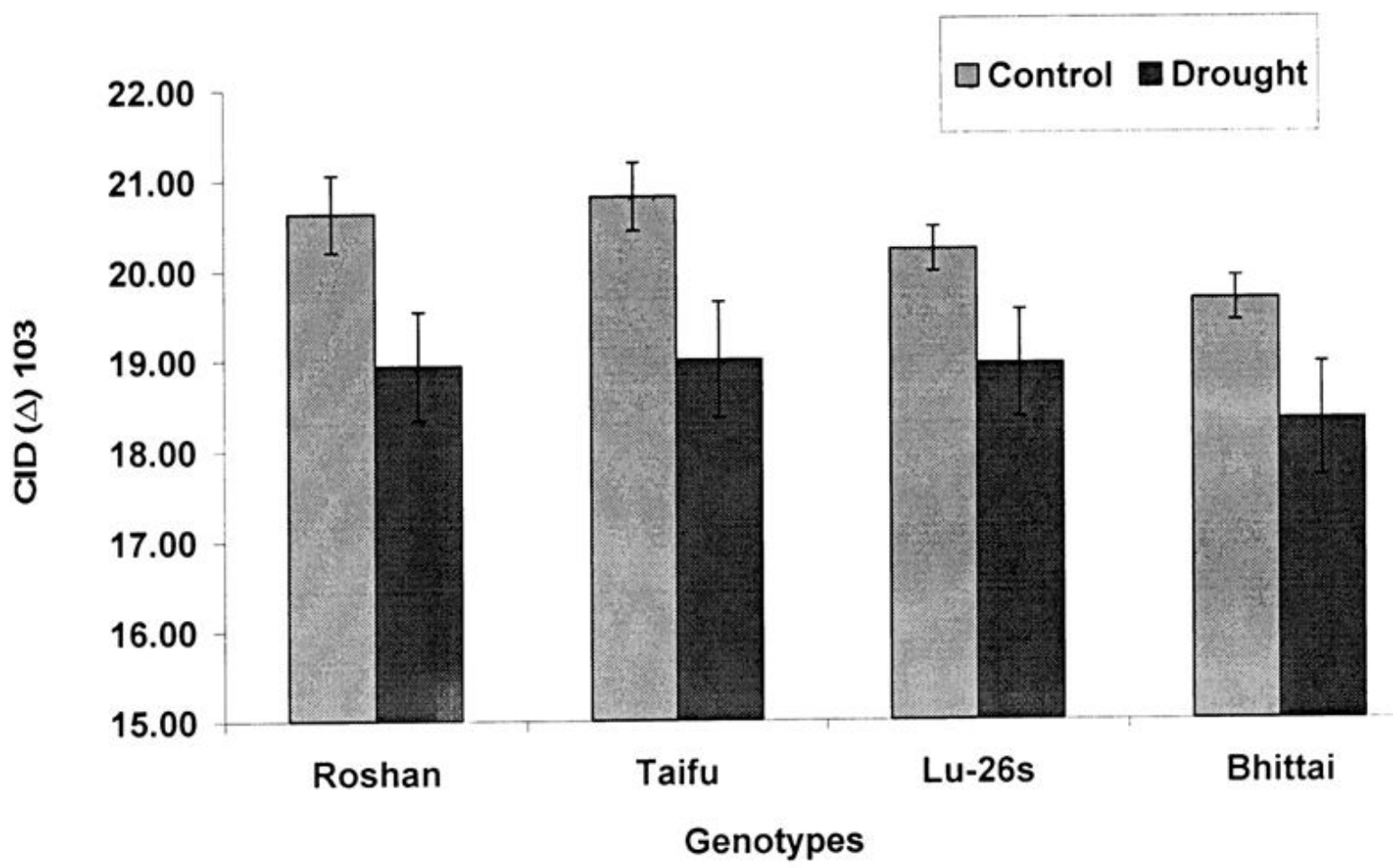

Fig. 1 CID in different wheat genotypes under normal and drought conditions.

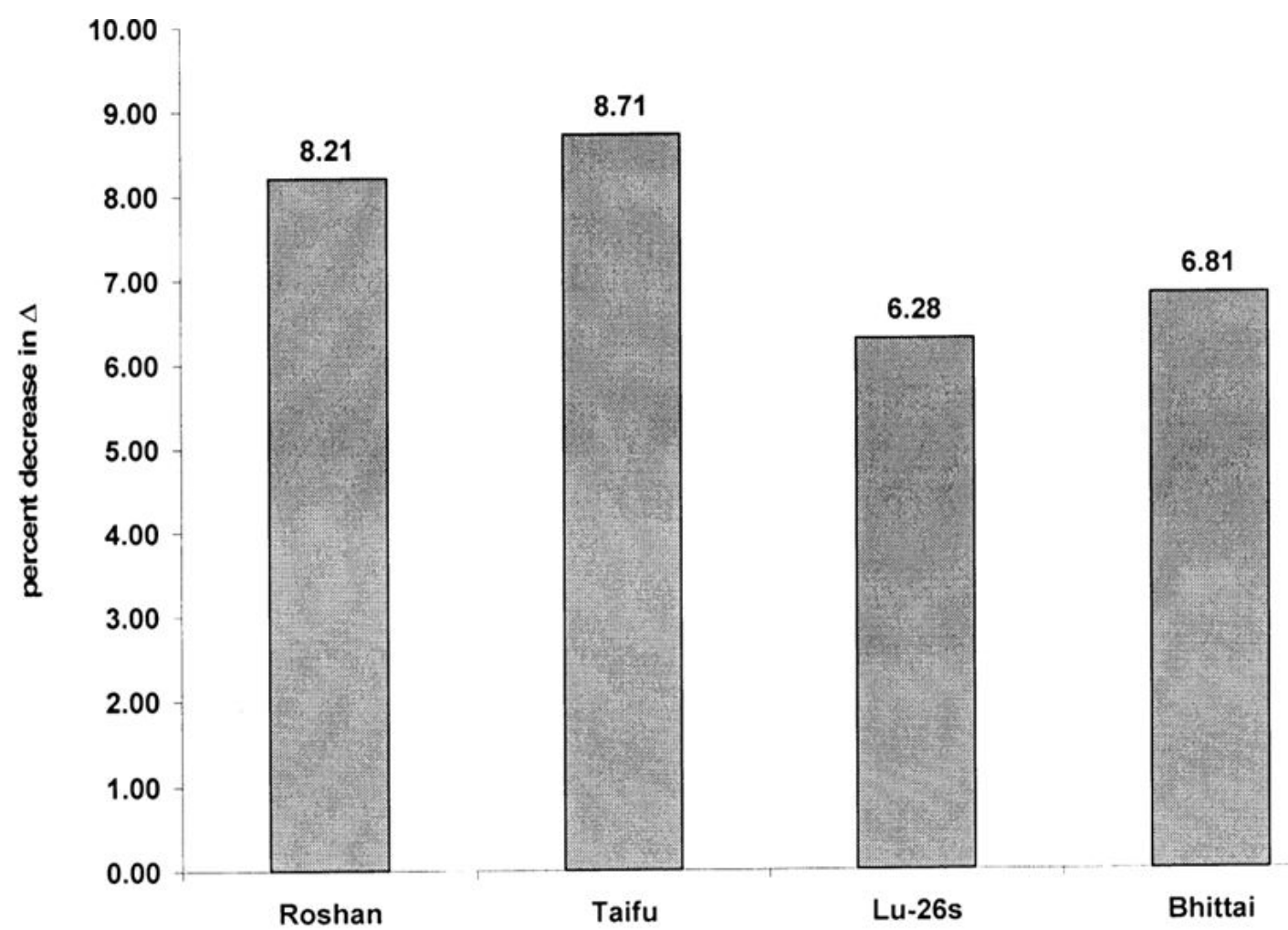

Fig. 2 Relative decrease in CID values as affected by drought. 


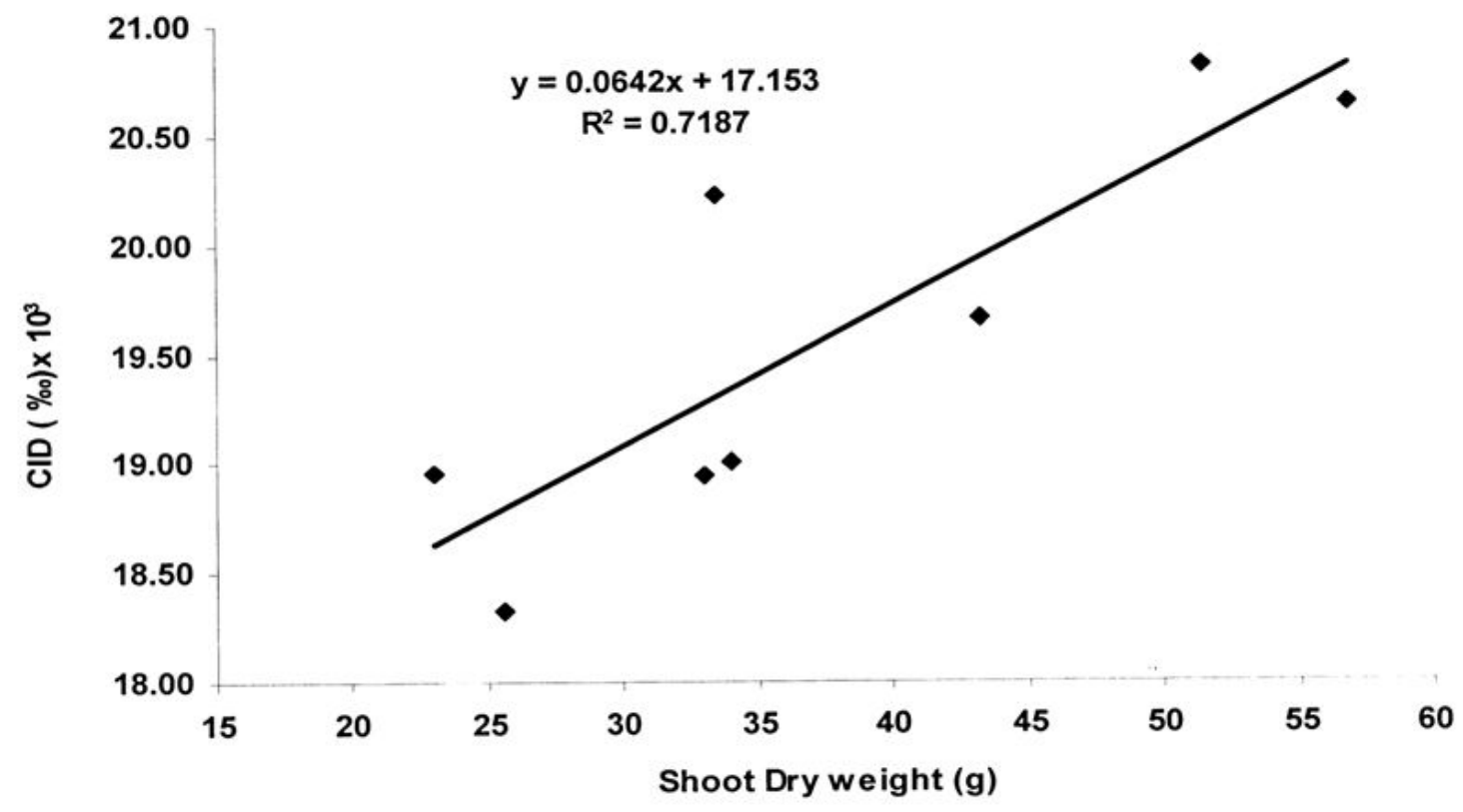

Fig. 3 Correlation between SDW and CID in wheat under drought condition.

The variation between the values under well watered and drought condition indicates that the wheat genotypes significantly discriminate between heavier and lighter carbon during photosynthesis. It is also reported that the variation in CID in cereals is known to arise from variation in photosynthetic capacity as well as stomatal conductance [9, 10]. Many authors have suggested that $\Delta$ could also be related to $\mathrm{GY}$ (grain yield) and WUE (water use efficiency) [11], the dry matter production to water consumption ratio [12]. It has been shown in earlier studies on wheat that drought stress leads to noticeable decrease in photosynthetic rate as well as stomatal and mesophyll conductance [13]. In the present study, comparatively higher reduction in SDW of Taifu might be due to more decrease in photosynthetic activity. On the other hand, less reduction in SDW in LU-26s showed the stability in photosynthetic activity under drought conditions, which might have resulted in maintaining SDW of this genotype.

Less reduction in SDW in LU-26s is also well supported by less reduction in CID values (i.e., only $6.28 \%$ ). On the other hand the genotypes Taifu and Bhittai though had higher values of SDW under normal water regimes but could not maintain it successfully under drought conditions and showed 54\% and 51\% decrease, respectively, indicating their more sensitivity to drought. The high sensitivity of these genotypes is well supported by higher reduction in CID values (i.e., $8.71 \%$ and $6.82 \%$, respectively). Similarly low values of SDW and higher reduction in CID values in Roshan (8.21\%), also indicate higher sensitivity to drought by this genotype.

\section{Conclusion}

The carbon isotopic discrimination is provided useful approach to make criteria of wheat to drought tolerant. It is therefore concluded that CID technique can be successfully used as an effective criterion for the selection of drought tolerant genotypes in wheat. The high values of $\Delta$ suggest that the genotypes more sensitive to drought conditions.

\section{Acknowledgements}

The support of the IAEA-Technical Cooperation Project program for this experiment is gratefully acknowledged. We would like to thank also to soil and water management, and crop nutrient laboratory, Joint FAO/IAEA Laboratory, Seibersdorf, Austria for facilities and sample measurements. 


\section{References}

[1] Qain, Y. L., Follett, R. F., Wilhelm, S., Koski, A. J., and Shahba, M. A. 2004. "Carbon Isotopes Discrimination of Three Kentucky Bluegrass Cultivars with Contrasting Salinity Tolerance." Agronomy Journal 96: 571-5.

[2] Condon, A. G., Richard, R. A., and Farquhar, G. D. 1990. "Genotypic Variation in Carbon Isotopes Discrimination and Transpiration Efficiency in Wheat: Leaf Gas Exchange and Whole Plant Studies." Aust. J. Plant. Physiol. 17: 9-22.

[3] Ehdai, B., Hall, A. E., Farquhar, G. D., Nguyen, H. T., and Waines, J. G. 1991. "Water Use Efficiency and Carbon Isotopes Discrimination in Wheat." Crop Science 31: 1282-8.

[4] Johnson, R. C., Asay, K. H., Tieszen, L. L., and Ehleringer, J. R. 1990. "Carbon Isotope Discrimination: Potential for Screening Cool Season Grass for Water Limited Environments.” Crop Science 30: 338-43.

[5] Johnson, R. C. and Bassett, L. M. 1991. "Carbon Isotopes Discrimination and Water Use Efficiency in Four Season Grasses." Crop Science 31: 157-62.

[6] Hubick, K. T., Farquhar, G. D., and Shorter, R. 1986. "Correlation between Water Use Efficiency and Carbon Isotopes Discrimination in Diverse Peanut (Arachis) Germplasm.” Aust. J. Plant Physiol. 13: 803-16.
[7] Anonymous. 1991. MSTAT Micro-Computer Statistical Programme. Michigan State, Michigan Lansing, USA: University of Agriculture.

[8] Farquhar, G. D., Hubick, K. T., Condon, A. G., and Richards, R. A. 1988. "Carbon Isotope Discrimination and Water Use Efficiency." In Stable Isotope in Ecological Research, edited by Rundel. New York: Springer-Verlag, pp: 21-46.

[9] Condon, A. G., Richard, R. A., and Farquhar, G. D. 1987. "Carbon Isotopes Discrimination Is Positively Correlated with Grain Yield and Dry Matter Production in the Field Grown Wheat." Crop Science 27: 996-1001.

[10] Morgan, J. A., and LeCain, D. R. 1991. "Leaf Gas Exchange and Related Leaf Traits among 15 Winter Wheat Genotypes." Crop Science 31: 443-8.

[11] Clay, D. E., Clay, S. A, Liu, Z., and Reese, C. 2001. "Spatial Variability of 13-C Isotopic Discrimination in Corn." Commun. Soil Sci. Plant Anal. 32 (11 \& 12): 1813-27.

[12] Monneveux, F., Reynolds, M. P., Trethowan, R., Pena, R. J., and Zapata, F. 2005. "Relationship between Grain Yield and Carbon Isotope Discrimination in Bread Wheat under Four Water Regimes.” Eur. J. Agron. 22: 231-42.

[13] Shaheen, R., and Hood-Nowotny, R. C. 2005. "Effect of Drought and Salinity on Carbon Isotope Discrimination in Wheat Cultivars." Plant Science 168: 901-9. 